\title{
Effects of Instant Messaging on the Management of Multiple Project Trajectories
}

\author{
Susan R. Fussell, Sara Kiesler, \\ Leslie D. Setlock, Peter Scupelli \\ Human Computer Interaction Institute \\ Carnegie Mellon University \\ 5000 Forbes Avenue \\ Pittsburgh, PA 15213 USA \\ susan.fussell@cmu.edu \\ +1 412-268-7125
}

\begin{abstract}
We present a study of the effects of instant messaging (IM) on individuals' management of work across multiple collaborative projects. Groups of four participants completed four web design tasks. Each participant worked on two tasks, each task with a different partner who was either co-located or remote, connected via IM. In one condition, each participant had one co-located and one remote partner. In a second condition, both partners were remote. We examined communication, division of labor, and task performance as a function of condition. The results indicated that nearly all participants divided their time unequally between projects, but less unequally in the remote/remote condition. In the co-located/remote condition, participants favored the task with the co-located partner. The results show that the effects of IM differ depending on people's multiple tasks are distributed across space. We propose a new IM interface that promotes awareness of multiple collaborators on multiple tasks.
\end{abstract}

\section{Categories and Descriptors}

H.5.3 Group and Organization Interfaces. Collaborative Computing.

\section{General Terms}

Design, Experimentation, Human Factors, Theory

\section{Keywords}

CSCW, distributed work, empirical studies, collaborative writing, coordination mechanisms, intellectual teamwork

\section{INTRODUCTION}

In this paper, we consider the effects of instant messaging (IM) - semi-synchronous text-based communication —on

\footnotetext{
Permission to make digital or hard copies of all or part of this work for personal or classroom use is granted without fee provided that copies are not made or distributed for profit or commercial advantage and that copies bear this notice and the full citation on the first page. To copy otherwise, or republish, to post on servers or to redistribute to lists, requires prior specific permission and/or a fee. CHI 2004, April 24-29, 2004, Vienna, Austria.

Copyright 2004 ACM 1-58113-702-8/04/0004...\$5.00.
}

\author{
Suzanne Weisband
}

\author{
Dept. of Management Information Systems \\ University of Arizona \\ 1130 East Helen Avenue \\ Tucson, AZ 85721 USA \\ weisband@eller.arizona.edu \\ +1 520-621-8303
}

workers' ability to coordinate their trajectories of work across multiple projects and teams. We use the term "trajectory" to refer to the sequence of activities through which a person, resource, or team moves [2]. For information workers, work trajectories include individual tasks that comprise stages in a project, communication, and other coordination activities for each of their assigned projects. At an organizational level, successful trajectory management refers to the completion of all important projects and to the ability of personnel to work effectively on their multiple projects.

Trajectory management is a particularly difficult coordination problem [19]. When people are working on one of their tasks, they usually cannot be working on a different task. Choices about which project to work on thus have consequences not only for the success of the selected project but also for the success of all the non-selected ones. Previous research [e.g., 16] has typically focused either on team coordination within a single project or on task coordination for a single individual over time. Here, we consider how personnel and tasks are coordinated at the organizational level.

When collaborators are co-located, they can coordinate work on multiple projects through informal communication and passive awareness of workplace activities [16]. Trajectory management among distributed team members is much more difficult because people lack awareness of the other projects and events that influence remote partners' work trajectories [e.g., 7, 12, 20]. Recently, several studies have suggested that instant messaging facilitates remote coordination $[10,11,14,18,22]$. For example, team members can use IM to set up meetings, ask questions of one another, or discuss project activities as the need arises.

Although IM is promising as a tool for remote coordination of people and tasks, it is unclear how well it supports distributed work when people have multiple work trajectories that include both co-located and remote projects. It is possible that IM-supported distributed projects will receive as much attention and effort as will tasks with co-located partners who can talk in person. On the other hand, the high salience of local projects and 
events might instead lead people to favor their projects with co-located partners, even when IM helps them connect in almost real time to distant partners.

In this paper, we examine the effects of IM on the coordination of multiple projects. We examine the trajectory management strategies of co-located partners and partners located at a distance using IM to help coordinate their activities. Our focus in particular is on how patterns of trajectory management differ depending upon whether people are working on both a co-located and a remote project versus two remote projects. Our goal is to understand how the physical distribution of team members and the communication medium used to support the task affects the success of both projects.

We first present the theoretical background of our study. Then, we present findings from a laboratory study in which groups of four participants completed four website development tasks. Each participant was assigned to two of the tasks, each with a different partner. In one condition, one partner was co-located and the other was remote; in a second condition, both partners were remote and communicated using IM. We examined communication, division of labor, and task performance as a function of condition. We conclude with recommendations for the design and implementation of technologies to facilitate trajectory management when people are working on multiple projects with different collaborators.

\section{TRAJECTORIES IN COLLABORATIVE WORK}

Much previous work on collaboration has focused on within-team co-located and distributed work. In the real world, however, people often belong to multiple work teams and they may work on different projects during the same weeks or months. By spending time working on one project, a person's actions affect not only other members of that project team but also members of all the other projects whose work they must postpone. To capture these phenomena and the issues they raise, we have adopted the concept of trajectories [2]. Trajectories are sequences of activities through which people, tasks, or teams move. In writing a research paper, for example, collaborators move through project initiation, data collection and analysis, and writing phases [17]. In the course of performing such a collaborative task, there are two key types of trajectories: participant trajectories (e.g., a team member accomplishes his or her assigned activities) and task trajectories (e.g., the project moves from initial stages to completion).

Although scheduling algorithms can be used as a starting point for coordinating multiple participants and projects, the dynamic nature of intellectual work makes pre-set schedules untenable in most situations. Each phase of a project may last longer than anticipated, as problems and delays arise. Collaborators may encounter unexpected new tasks that influence how much time they can put into a given project. The important aspect of such delays, from an organizational perspective, is that changes to any given collaborator's work trajectory will affect those of the others, as well as the entire set of projects.

\section{Effects of Distance on Coordination}

There are reasons to expect that physical distance between team members will increase the difficulty of trajectory coordination. Numerous studies have suggested that coordination of work in knowledge-based organizations is accomplished most effectively through spontaneous, informal talk in a co-located environment [e.g., 1, 16]. Colocation fosters awareness, spontaneous conversation, project focus, problem solving, and the development of social relationships $[6,15,20,21,23,24]$. Many distributed projects fail or get bogged down in delays [12], misunderstandings [7], and local distractions [20].

Despite the benefits of co-location, collaborators' work trajectories often require that they be physically distributed. Computer and telecommunications technologies, which facilitate resource sharing and communication across distance, make these arrangements possible.

\section{IM as a Trajectory Management Tool}

Recently, researchers have focused on the use of IM to support coordination of distributed work [e.g., 10, 11, 14, $18,22]$. IM has several advantages over more conventional media such as email. An important advantage is that IM supports impromptu conversations like those possible among co-located workers. Workers use IM for negotiating availability, asking quick questions, and discussing task activities. Buddy lists can serve as a reminder that work is required on a project, much as seeing someone in the hallway. Furthermore, IM makes it easy for people to interrupt one another and to change the course of each other's work trajectories [8].

The potential for IM to serve as a successful remote trajectory management tool gives rise to some questions about how people manage work trajectories that include both co-located and remote projects. If co-located and remote projects are equally important, does IM provide enough support for awareness and communication that IMbased remote projects are given equal weighting? Or does the high salience of co-located people and activities create an imbalance in work efforts, such that co-located projects are favored? We investigated this issue by comparing how people organized their work across two projects when both projects were done with remote partners or when one project was done with a co-located partner and the other with a remote partner. Using this paradigm, we were able to evaluate how IM helps people structure their work within the context of all their other projects.

\section{The Current Study}

In the current study, we examined work effort, communication, division of labor, teamwork, and subjective performance when participants engaged in two different web page development tasks with a different partner on each task. We compared two between-subjects 
conditions. In the Co-located/Remote (CR) condition, the partner for one task was co-located and the partner for the other task was remote. In the Remote/Remote (RR) condition, the partners for both tasks were remote. Colocated partners could communicate face-to-face and, if they wished, by IM. Remote partners communicated exclusively by IM. We examined five hypotheses regarding the effects of these conditions on our dependent variables:

- Task Effort: From previous research on distributed work, we hypothesized that participants in the Colocated/Remote condition would distribute their effort unevenly across their two projects. We expected participants to put more than half of their effort into the task with the co-located partner. We expected participants in the Remote/Remote condition to distribute their effort evenly between each partner and task.

- Communication: We hypothesized that participants in the Co-located/Remote condition would spend more time talking to their partners on their co-located task than they would with their partners on their remote task. We expected participants in the Remote/Remote condition to talk equally with their partners in their two projects.

- Division of labor: We hypothesized that all remote project pairs (i.e., all the Remote/Remote pairs and the remote pairs in the Co-located/Remote condition) would be likely to divide their remote task work into definable subtasks (e.g., writing content, html implementation) that would permit each partner to work independently. We expected co-located partners to work more collaboratively on each subtask of the project.

- Teamwork: We hypothesized that teamwork would be rated highly by co-located partners in the Co-located/ Remote condition because of the ease of communication. We further hypothesized that teamwork would be rated poorly in remote pairs in the Co-located/Remote condition because participants would devote more of their attention to their task with the co-located partner than to the task with the remote one. Teamwork in the Remote/ Remote condition was expected to fall in between.

- Outcome Evaluations: We hypothesized that participants would perceive their websites to be highest in quality when this task was done with a co-located partner in the Co-located/Remote condition, lowest in quality when the task was done with a remote partner in the Co-located/Remote condition, and of intermediate value when both task were done with two remote partners, that is, in the Remote/Remote condition.

\section{METHOD}

\section{Design}

Four-party groups worked in pairs to complete two web page design tasks per participant. Each participant worked with two partners, one on each of the tasks. In the Colocated/Remote condition, one partner was in the same room and the other was in a different room. In the
Remote/Remote condition, both partners were in different rooms (Table 1). Remote pairs could communicate and exchange files using IM. Participants could organize their work across the tasks in any way they saw fit, but had to complete both tasks during a one-hour period. Communication $\operatorname{logs}$, computer usage, and postexperimental surveys were used to analyze how tasks were organized across individuals, pairs, and groups.

Table 1. Sample task assignment for the Remote/Remote condition.

\begin{tabular}{|l|c|c|}
\hline & \multicolumn{2}{|c|}{ Room 1 } \\
\hline Room 2: & Participant 1 & Participant 2 \\
\hline Participant 3 & Task A & Task B \\
\hline Participant 4 & Task C & Task D \\
\hline
\end{tabular}

NOTE: Participants 1 and 2 are in Room 1; Participants 3 and 4 are in Room 2. Participant 1 works with Participant 3 on Task $A$ and with Participant 4 on Task C. In the Colocated/Remote condition, participants in the same room worked together on one of their two tasks.

\section{Participants}

Pretest participants consisted of 90 undergraduates at the University of Arizona, who completed a brief survey as part of their regular class activities. Participants in the main study consisted of 88 undergraduate students at Carnegie Mellon University. They received $\$ 15$ for participating, plus the opportunity to compete for $\$ 100, \$ 50$, and $\$ 25$ bonus prizes for the participants with the best, second best, and third best two web pages as indicated by external raters.

\section{Materials}

Tasks. Four web page design tasks were selected through a pretesting process. Ninety undergraduates at the University of Arizona rated their interest and prior knowledge of 21 health-related topics using seven-point scales $(1=$ low, $7=$ high). Based on mean ratings, we selected four topics - cloning, artificial blood, drinking water, and killer bees-with similar interest and knowledge profiles (M interest $=4.26$ to 4.73 ; $\mathrm{M}$ knowledge $=1.78$ to 2.64 ).

Webpage materials. For each task, a folder was created that contained a document of 730-780 words with a technical description of the subject matter, a set of eight images from which participants could select two for their web pages, and an instruction sheet providing a brief description of the task (i.e., the topic of the web page and basic points it should cover).

Surveys. A pretest survey was used to collect demographic information and participants' self-rated experience in website development. A post-experimental survey asked participants to assess each project/partner combination in terms of team responsibilities, team process, and task performance. One set of questions concerned the extent to which they had worked on seven elements of the web page 
design task ( 0 to $100 \%$ effort); a second set pertained to the quality of their teamwork with each partner $(1=$ strongly disagree; $7=$ strongly agree); and a third set addressed the quality of their final web pages $(1=$ very poor; $7=$ outstanding). A final set of questions asked participants to rate how well they coordinated their efforts across both projects (e.g., "It was difficult to decide how to allocate my time across my two projects," "I was always interrupting one task in order to work on the other one"), using a scale of 1 (strongly disagree) to 7 (strongly agree).

\section{Equipment}

Participants were assigned to a desk and computer running the Windows operating system. Two desks were positioned at 90 degree angles from one another in each of two laboratory rooms. Each machine was equipped with Microsoft FrontPage, Microsoft Word, Microsoft Internet Explorer, and AOL Instant Messenger (AIM).

Four Sony WCS-999 wireless lapel microphones were used to record speech. The output was fed into an ECHO MONA four-channel mixer for recording. Cool Edit Pro software was used to record the four channels in real time. After each session, Cool Edit Pro was used to mix the feeds from participants in the same room together.

\section{Procedure}

Participants were told that they would be working with partners to design web pages for a simulated health agency, and that their task would be to take scientific material and rewrite it for a general audience. This task included reading the original scientific report, rewriting the report for laypersons, adding pictures, and doing the layout and design of the web pages. Participants were told that they would be assigned two different projects at the same time, each with a different partner. Both tasks had to be completed in a one-hour period and upon completion of the study, the people with the top three pairs of websites would be awarded $\$ 100, \$ 50$ and $\$ 25$ prizes.

Prior to beginning the experiment, participants were shown how to use the software. Each participant was then given two instruction sheets listing the title of each project and his/her partner for that project. To ensure that participants understood the need to coordinate their work across both projects, the experimenter stressed that the people with the two best web pages would receive bonus prizes.

\section{Dependent Measures}

Work effort. Work effort was computed from keystroke activity logs. The logs recorded which application a participant was using. Post-processing software was used to identify which task a participant was working on. For the analyses reported here, we aggregated across all keystrokes in all applications within each task. Individuals' work effort for a task was defined as the total computer time spent working on that task. Effort scores computed with and without IM time included were highly correlated, so we report results using total effort.
Communication. We transcribed the audio tapes of the colocated work sessions. Perl scripts were used to generate word counts per task for audio transcripts and IM logs.

Division of labor. Participants' estimated effort on each of seven elements of the web page design task were factor analyzed with Varimax rotation (Table 2). A two-factor solution accounted for $81 \%$ of the variance. Factor I ("Development," $57 \%$ of variance) included deciding on visual content, page layout, and colors/fonts as well as creating navigation tools and implementing the design in FrontPage. Factor II ("Content," 24\% of variance) included deciding on content and writing the text. We calculated scores for content and development by participant and task.

Table 2. Division of labor questions with factor loadings

\begin{tabular}{|l|c|c|}
\hline \multicolumn{1}{|c|}{ Division of Labor Questions } & Factor & Loading \\
\hline Deciding what content to include & Content & .91 \\
\hline Writing the text & Content & .91 \\
\hline Deciding on visual content & Develop & .85 \\
\hline Deciding on page layout & Develop & .94 \\
\hline Choosing colors and fonts & Develop & .90 \\
\hline Creating navigation tools & Develop & .79 \\
\hline FrontPage implementation & Develop & .93 \\
\hline
\end{tabular}

Teamwork. The 10 Team Process questions were subjected to Factor Analysis with Varimax rotation (Table 3). An initial two-factor solution distinguished only negatively versus positively worded questions. Therefore, we averaged all questions into a single teamwork scale.

Table 3. Teamwork questions and factor loadings

\begin{tabular}{|l|c|}
\hline \multicolumn{1}{|c|}{ Teamwork Questions } & Loading \\
\hline $\begin{array}{l}\text { My partner and I did our jobs without getting in } \\
\text { each other's way }\end{array}$ & .43 \\
\hline $\begin{array}{l}\text { My partner kept me up to date about what } \\
\text { he/she was doing }\end{array}$ & .76 \\
\hline It was easy to discuss the work with my partner & .77 \\
\hline $\begin{array}{l}\text { My partner finished his/her tasks in time for me } \\
\text { to do mine. }\end{array}$ & .73 \\
\hline $\begin{array}{l}\text { My partner and I often disagreed about who } \\
\text { should be doing what task (inverted). }\end{array}$ & .21 \\
\hline My partner and I wasted a lot of time (inverted). & .40 \\
\hline $\begin{array}{l}\text { My partner and I agreed about what our website } \\
\text { should look like. }\end{array}$ & .61 \\
\hline My partner treated me fairly. & .74 \\
\hline $\begin{array}{l}\text { My partner had a definite sense of direction and } \\
\text { purpose. }\end{array}$ & .75 \\
\hline $\begin{array}{l}\text { If given the choice, I would work with this } \\
\text { partner again. }\end{array}$ & .81 \\
\hline
\end{tabular}


Task performance. Participants' ratings of their final web pages were factor analyzed with Varimax rotation. One factor accounted for $61 \%$ of the variance. We averaged ratings to measure task performance (Table 4).

Table 4. Task performance questions and factor loadings

\begin{tabular}{|l|c|}
\hline \multicolumn{1}{|c|}{ Task performance questions } & Loading \\
\hline Usefulness/quality of content & .77 \\
\hline Writing quality & .72 \\
\hline Usefulness/quality of visual content & .84 \\
\hline Use of colors/fonts. & .80 \\
\hline Page layout and use of space. & .86 \\
\hline Navigation functionality/clarity. & .72 \\
\hline FrontPage implementation. & .75 \\
\hline
\end{tabular}

\section{RESULTS}

We discuss the results in three sections. First, we consider how individual participants coordinated their activities across their two projects. Second, we examine how pairs of collaborators coordinated their activities within a single project. Finally, we look briefly at how entire groups distributed their work across all participants and projects.

\section{Individual Coordination Across Projects}

We first analyzed the data by comparing individuals' work effort and survey responses for their two tasks as a function of condition (Co-located/Remote vs. Remote/Remote) and the location of their partners (co-located vs. remote).

Work effort. We hypothesized that work effort would be higher by co-located pairs on their task in the Colocated/Remote condition than for remotely done tasks in either condition. As predicted, mean effort was highest for co-located work in the $\mathrm{CR}$ condition, lowest for remote work in the $\mathrm{CR}$ condition, and intermediate for both remote tasks in the RR condition (Figure 1). A 2 (condition [CR or RR]) by 2 (pairs' locations]) by 4 (task) ANOVA showed significant effects of condition ( $\mathrm{F}[1,100]$ $=14.62, \mathrm{p}<.001)$, pairs' locations $(\mathrm{F}[1,100]=29.81, \mathrm{p}$ $<.0001)$, and task $(\mathrm{F}[3,100]=3.33, \mathrm{p}<.05)$. These findings suggest that the effect of IM on work effort in a remote task depended on the overall work organization-specifically, whether participants' other task was conducted with another remote partner or with a colocated partner.

The preceding analysis grouped all IM supported work in the RR condition and compared this work to the co-located and remote work done in the CR condition. We were curious whether the RR means masked an uneven distribution of labor similar to that in the CR condition. We determined for each person a favored task, on which they spent the greater part of their time, and a non-favored task, on which they spent less time.

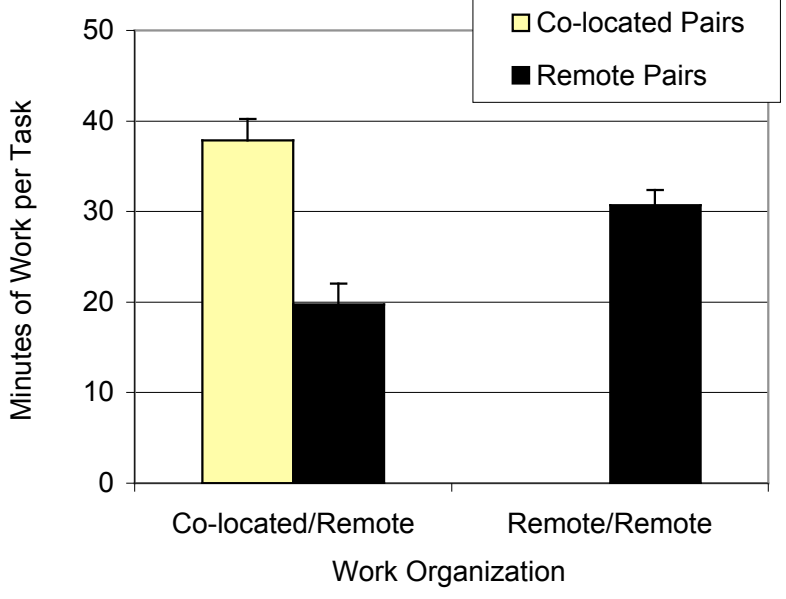

Figure 1. Total minutes of effort per task by condition and pair location.

To our surprise, participants in the RR condition strongly favored one of their tasks just as did participants in the CR condition (Figure 2). A 2 (condition) by 2 (favored vs. unfavored task) ANOVA on effort expended indicated a strong effect of favored task $(\mathrm{F}[1,138]=316.80, \mathrm{p}<$ .0001 ), indicating that people spent significantly more time on one of their two tasks in both conditions. In addition, there was a borderline significant condition by favored/nonfavored task interaction $(\mathrm{F}[1,138]=2.76, \mathrm{p}=.10)$, reflecting the fact that participants in the RR condition tended to distribute their effort slightly more evenly across their two projects.

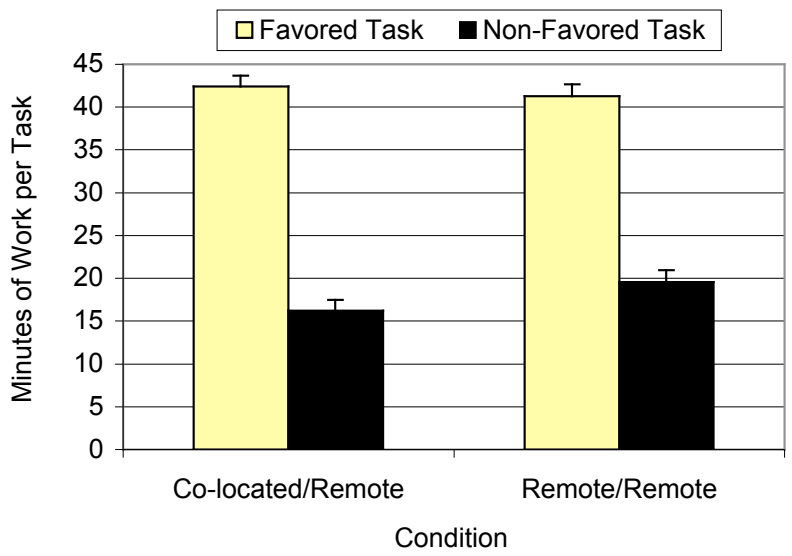

Figure 2. Mean minutes spent on favored and non-favored tasks by condition.

Division of labor. We hypothesized that remote pairs in both $\mathrm{CR}$ and $\mathrm{RR}$ conditions would be more likely to divide up their labor into definable subtasks. This hypothesis was not supported. All pairs appear to have divided up the work into subtasks corresponding to content and webpage development. A 2 (condition [CR or RR]) by 2 (pairs' locations) by 4 (task) ANOVA showed no significant effects. 
Teamwork. We hypothesized that participants would rate their teamwork highest for co-located work in the CR condition, because of the benefits of co-location for coordination. This hypothesis was weakly supported: Teamwork was rated higher among co-located pairs than for remote pairs $(\mathrm{Ms}=4.10$ and 3.80, respectively, on a scale of $1=$ low and $7=$ high teamwork). An ANOVA of the same design as that for division of labor showed a borderline significant effect of pairs' location $(\mathrm{F}[1,99]=$ $3.67, \mathrm{p}=.06$ ) but no other main effects.

Outcome Evaluations. We hypothesized that participants in co-located pairs would rate the quality of their web page highest, and that remote pairs in the CR condition would rate their web pages lowest in quality. This hypothesis was only modestly supported. An ANOVA showed a borderline significant effect of condition $(\mathrm{F}[1,100]=2.95, \mathrm{p}=.09]$ and a significant effect of pairs' location $(F[1,100]=$ $4.21, \mathrm{p}<.05)$. Web pages generated in co-located pairs were rated better than those done remotely $(\mathrm{M}=5.13$ and 4.72 , respectively, on a scale of 1-7), but there were no differences between the remote pairs in the CR condition and the other remote pairs in the RR condition.

\section{Coordinating Partners Within Tasks}

A second way to consider the data is in terms of task trajectories. We calculated for each task the amount of time each of the two participants worked on that task. Minutes spent working on the task by the two partners were correlated $.35(\mathrm{~N}=80, \mathrm{p}<.002)$. However, partners divided their labor: Correlations between partners' implementation and content efforts were -.65 and -.46, respectively $(\mathrm{p}<.0001)$. A 2 (condition) by 2 (pairs' locations) by 4 (task) ANOVA showed significant effects of condition $(\mathrm{F}[1,36]=10.40, \mathrm{p}<.005)$ and pairs' location $(\mathrm{F}[1,36]=21.95, \mathrm{p}<.0001)$.

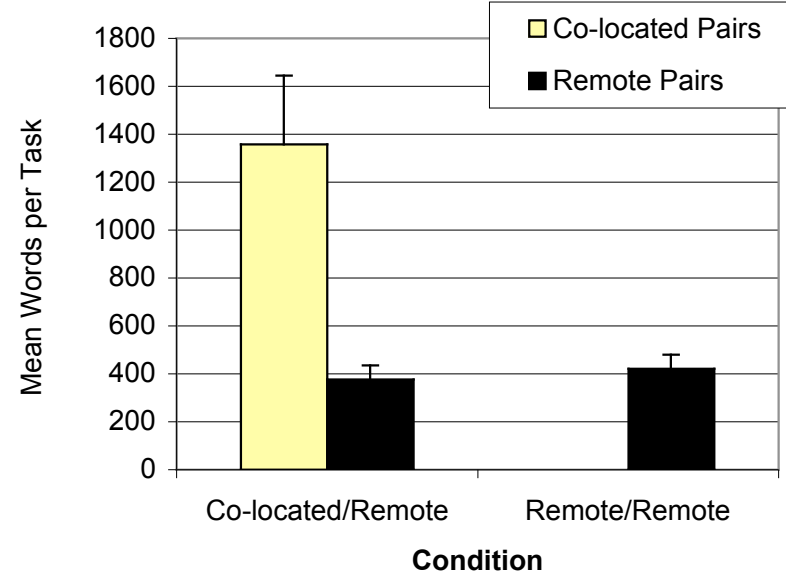

Figure 3. Words per task by condition and pair location.

Communication. Mean words expended by pairs on each task are shown in Figure 3 as a function of condition and pair location. As can be seen, participants spoke over three times as many words when they were co-located as they did when they typed remotely. Words per task by remote pairs did not differ as a function of condition. Thus, across both tasks, participants in the RR condition communicated significantly less than those in the CR condition.

\section{Group Coordination Across Projects}

The end result of the distribution of effort patterns reported above for individuals and tasks was an unequal distribution of effort at the group level across all four tasks. As shown in Figure 4, the 4-person groups that worked during one session tended to favor two of their four web page construction projects over the other two. This pattern of unequal distribution of effort across tasks was strikingly similar in the $\mathrm{CR}$ and RR conditions.

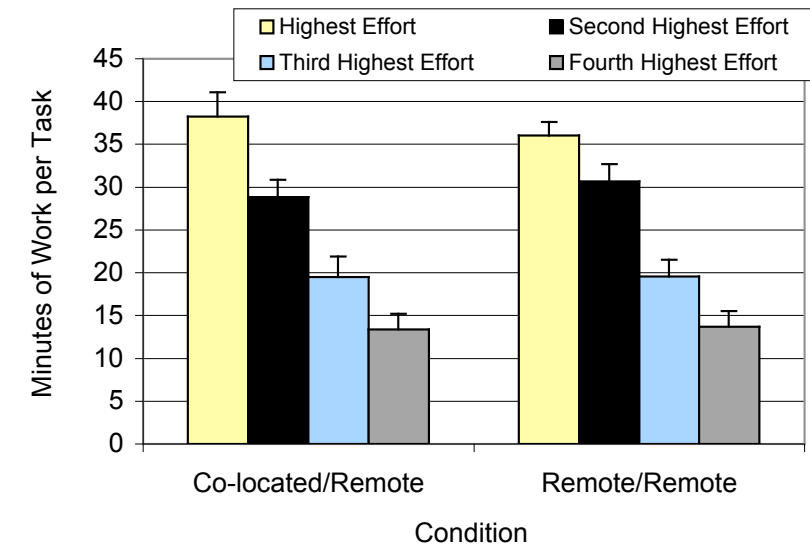

Figure 4. Distribution of effort across 4 tasks by condition.

\section{DESIGNING AN IM CLIENT FOR MANAGING MULTIPLE PROJECTS}

The design of technologies to help coordinate trajectories among distributed, busy people is a complex problem. Existing IM research can be split into two general types, one focusing on individual IM use and the other focusing on ways to support IM group chat for members of a project. We explore a third perspective that focuses on helping individual users manage multiple group projects with a new IM interface. We describe the motivation for this interface and present our current prototype.

Our findings suggest that collaborators have difficulties managing their time and effort across a set of co-located and remote projects. When workers have multiple tasks, those that can be accomplished face-to-face are given priority even when all tasks are of equal importance. This initial priority had consequences for participants' other work: they spent more than half their time on the first task, leaving insufficient time for the second one.

One of the primary difficulty pairs faced was coordinating the onset of work on the second of two projects. People had to ascertain when their partners were finished with one task and ready to begin their mutual task. In our study, much of this coordination took place via conversation. As the number of projects and collaborators rises, however, the 
effectiveness of coordinating effort via communication is likely to decrease.

In addition, as the numbers of projects in one's work trajectory increases, it becomes more difficult to keep them all in mind and to recognize when one is spending too much effort on one task to the detriment of others. As we have noted, memory lapses have a trickle-down effects, causing delays for people's collaborators on all their different projects. In our experiment, participants could use the structure of the experiment and the knowledge that they had only two tasks to estimate when to switch. In larger organizational contexts where people may have many projects, it is much easier for them to forget their task. Researchers have integrated to-do lists with email [3]; here, we examine a simple type of to-do list, a list of projects one is associated with, integrated into an IM client.

\section{The Project-View IM Interface}

Our proposed solution to problems of memory and trajectory management is to modify IM interfaces to provide both individual and task-related information. Based on our results, we suggest that IM would facilitate trajectory management if it included three features:

- An awareness component that provides information about collaborators' general activities and availability.

- An information component that provides an indication of when collaborators are engaged in a joint task.

- A reminder component that provides an abbreviated todo style indicator of the activities one needs to attend to.

In Figure 5, we present the Project-View IM interface that meets these needs. Project-View shows traditional buddy information that provides general awareness of whether collaborators are online and available. It also shows a list of all one's group projects as a reminder of one's collaborative responsibilities. Project-View thus helps people monitor both their personal trajectories, by serving as a memory aid, and their task trajectories, by showing how many team members are working on a project at any given moment. Privacy is protected by limiting the information a user can have about another person to that pertaining to their joint projects. The benefits of ProjectView are that it builds on current IM applications so that users aren't forced to learn a new application, it conveys information in a minimally distracting way, and it minimizes privacy concerns.

The Project-View interface facilitates dividing attention across multiple projects without disrupting one's primary task. Human factors research suggests that parallel processing aids divided attention [25]. To encourage parallel processing, we implemented color coding; grouped related information together, and added information about a person's current project to the buddy list. In addition, Project-View permits users to expand or contract the project lists just as they can expand and contract buddy lists in most IM clients. As shown on the left of Figure 5, the unexpanded project list provides a list of all one's projects and an indicator of how many people are currently working on that project. On the right, the list is expanded to provide information about all project members.

\begin{tabular}{|c|c|}
\hline$=\square x$ & $=\square \times$ \\
\hline File Actions Tools Help & File Actions Tools Help \\
\hline $\begin{array}{l}\text { My Status: } \\
\text { |l|| Leslie (online) IM Interface }\end{array}$ & $\begin{array}{l}\text { My Status: } \\
\| \text { Leslie (online) IM Interface }\end{array}$ \\
\hline $\begin{array}{l}\text { (2) My Buddy list (3/7) } \\
\text { NSF proposal } \\
\text { Bil| Sub (away) } \\
\text { Suzie (offline) } \\
\text { Joyce (away) } \\
\text { Kelly (online) } \\
\text { Michele (offline) } \\
\text { Sara (online) }\end{array}$ & $\begin{array}{l}\text { (2) My Buddy list (3/7) } \\
\text { NSF proposal } \\
\text { Bine (online) } \\
\text { Bob (away) } \\
\text { Suzie (offline) } \\
\text { Joyce (away) } \\
\text { Kelly (online) } \\
\text { Michele (offline) } \\
\text {.|l Sara (online) }\end{array}$ \\
\hline $\begin{array}{l}\text { (2) My Project List } \\
\text { (NSF proposal (1 working) } \\
\text { ER study (0 working) } \\
\text { IM Interface (1 working) }\end{array}$ & $\begin{array}{l}\text { (2) My Project List } \\
\text { (a) NSF proposal (1 working) } \\
\text { (8) Eue (NSF proposal) } \\
\text { \& IM Interface (1 working) }\end{array}$ \\
\hline
\end{tabular}

Figure 5. The Project-View IM interface designed to support both multiple collaborators and multiple projects.

\section{DISCUSSION}

The results of our laboratory study suggest three key conclusions: first, participants have difficulty dividing their time evenly across multiple projects of equal importance; second, participants with both co-located and remote partners tend to favor their co-located tasks; and third, the effects of IM on work effort differs as a function of the larger organization of a person's work life. We proposed a novel IM interface that is intended to facilitate individual and task trajectory management by providing information about others' task-relevant activities.

Our experimental paradigm was designed to look at people's efforts across two similar tasks of equal priority. A next step for this work is to examine how co-location vs. distribution of projects affects work efforts among dissimilar tasks, tasks with different priorities or payoff structures. Our study also used equal status pairs who had equal investment in the task, whereas many real-world settings involve formal and informal leadership structures that may influence how distance affects trajectory management. Finally, our teams consisted of unacquainted individuals. Prior research suggests that when workers are familiar with one another, remote collaboration is easier [9]. Future research will need to examine whether the 
imbalances in effort seen in our CR teams remain when both co-located and remote projects involve familiar team members.

\section{ACKNOWLEDGEMENTS}

This material is based upon work supported by the National Science Foundation under Grants \#9872996, \#0325087 and \#0329077. Any opinions, findings, and conclusions or recommendations expressed in this material are those of the authors and do not necessarily reflect the views of the National Science Foundation. We thank Katherine Bankson, Mariesa Cash, Adam Kramer, Marina Kobayashi, Kathy Lau, Elizabeth Parker and Jim Zheng for their assistance in running experiments and coding data.

\section{REFERENCES}

1. Allen, T. J. \& Hauptman, O. (1987). The influence of communication technologies on organizational structure: A conceptual model for future research. Communication Research, 14,575-587.

2. Bardram, J. E. (2000). Temporal coordination. Computer supported cooperative work, 9, 157-187.

3. Bellotti, V., Ducheneaut, N., Howard, M., \& Smith, I. (2003). Taking email to task: The design and evaluation of a task management centered email tool. Proceedings of CHI 2003. NY: ACM Press.

4. Boh, W. F., Ren, Y., \& Kiesler, S. (2002). Utilizing expertise in distributed environments. International Congress of Information Systems, Barcelona, Dec.

5. Bradner, E., Kellogg, W. A., \& Erickson, T. (1998). Babble: Supporting conversation in the workplace. ACM SIGGROUP Bulletin, 19.

6. Bradner, E., \& G. Mark. (2002). Why distance matters: Effects on cooperation, persuasion, \& deception. Proceedings of $C S C W^{\prime} 02$ (pp. 226-235). NY: ACM Press.

7. Cramton, C. D. (2001). The mutual knowledge problem and its consequences for dispersed collaboration. Organizational Science, 12, 346-371.

8. Cutrell, E. B., Czerwinski, M., \& Horvitz, E. (2000). Effects of instant messaging interruptions on computing tasks. CHI 2000 Extended Abstracts (pp. 99-100). NY: ACM Press.

9. Grinter, R. E., Herbsleb, J. D., \& Perry, D. W. (1999). The geography of coordination: Dealing with distance in R\&D work. In Proceedings of SIGGROUP (pp. 306-315). NY: ACM Press.

10. Handel, M., \& Herbsleb, J. D. (2002). What is chat doing in the workplace? Proceedings of CSCW 2002 (pp. 1-10). NY: ACM Press.

11. Herbsleb, J. D., Atkins, D. L., Boyer, D. G., Handel, M., \& Finholt, T. A. (2002). Introducing instant messaging and chat in the workplace. Proceedings of CHI 2002. NY: ACM Press.
12. Herbsleb, J. D., Mockus, A., Finholt, T. A., \& Grinter, R. E. (2000). Distance, dependencies, and delay in a global collaboration. Proceedings of $\mathrm{CSCW}$ 2000 (pp. 319-328). NY: ACM Press.

13. Isaacs, E., A., Tang, J. C., \& Morris, T. (1996). Piazza: A desktop environment supporting impromptu and planned interactions. Proceedings of CSCW 1996 (pp. 315-324). NY: ACM Press.

14. Isaacs, E., Walendowski, A., Whittaker, S., Schiano, D. J., \& Kamm, C. (2002). The character, functions, and styles of instant messaging in the workplace. Proceedings of CSCW 2002 . NY: ACM Press.

15. Kiesler, S., \& Cummings, J. N. (2002). What do we know about proximity and distance in work groups? A legacy of research. In P. Hinds \& S. Kiesler (Eds.) Distributed work (pp. 57-80). Cambridge: MIT Press.

16. Kraut, R. E., Fish, R.S., Root, R.W., \& Chalfonte, B.L. (1990). Informal communication in organizations: Form, function, and technology. In S. Oskamp \& S. Spacapan (Eds). Human reactions to technology: The Claremont Symposium on applied social psychology (pp. 145-199). Beverly Hills, CA: Sage.

17. Kraut, R. E., Galegher, J., \& Egido, C. (1988). Relationships and tasks in scientific research collaborations. Human-Computer Interaction, 3, 3158.

18.Ljungstrand, P., \& Segerstad, Y. H. (2000). Awareness of presence, instant messaging and WebWho. Siggroup Bulletin, 21, 3, 21-27.

19. Malone, T. W. \& Crowston, K. (1994). The interdisciplinary study of coordination. $A C M$ Computing Surveys, 26, 87-119.

20. Mark, G., Grudin, J., \& Poltrock, S. E. (1999). Meeting at the desktop: An empirical study of virtually collocated teams. Proceedings of ECSCW' 99 (pp. 159-178). Dordrecht, Netherlands: Kluwer.

21. Nardi, B. A., \& Whittaker, S. (2002). The place of face-to-face communication in distributed work. In P. Hinds \& S. Kiesler (Eds.) Distributed work (pp. 83110). Cambridge, MA: MIT Press.

22. Nardi, B. A., Whittaker, S., \& Bradner, E. (2000). Interaction and outeraction: Instant messaging in action. Proceedings of CSCW 2000 (pp. 79-88). NY: ACM Press.

23. Olson, G. M., \& Olson, J. S. (2000). Distance matters. Human-Computer Interaction, 15, 139-179.

24. Weisband, S. (2002). Maintaining awareness in distributed team collaboration: Implications for leadership and performance. In P. Hinds \& S. Kiesler (Eds.), Distributed work. Cambridge: MIT Press.

2 5.Wickens, C. D., \& Hollands, J. G. (1999). Engineering psychology and human performance, $3^{\text {rd }}$. ed. Upper Saddle River, NJ: Prentice-Hall. 